\title{
US food safety overhaul in legislative limbo
}

Published at www.cmaj.ca on Oct. 26

I $\mathrm{f}$ there was any silver lining to the salmonella outbreak that led to the largest egg recall in United States history over the summer, it was hope that the incident would spur Congress to push through long-delayed legislation to overhaul the nation's food safety system.

Even that wasn't enough to dislodge the bill, although it has bipartisan support in Congress and backing from consumer, business and food industry groups.

Convoluted rules allowed one senator to block passage of the bill before legislators recessed in September. Supporters nonetheless are optimistic that the legislation will win approval during a lame-duck session after the November midterm elections.

"Not dead yet" seems to be the rallying cry for the FDA Food Safety Modernization Act.

The 225-page bill would bring about the most sweeping update of food safety rules in the United States in more than 50 years, giving the US Food and Drug Administration (FDA) more power to recall tainted products, requiring companies to develop food safety plans, improving the safety of imported foods and targeting inspections toward the foods most at risk of causing disease or illness. The House approved a version of the bill in March 2009 and a Senate committee unanimously approved it in November 2009.

According to the private Center for Science in the Public Interest, there have been more than 85 food recalls while the food safety legislation has languished over the past year, including recalls of lettuce, sprouts, peanut butter, spinach and cookie dough. More than a half-billion eggs were recalled this summer after as many as 1600 illnesses were linked to a salmonella outbreak.

"Congress has had more than enough evidence that the program isn't functioning effectively," says Caroline Smith DeWaal, the centre's director of

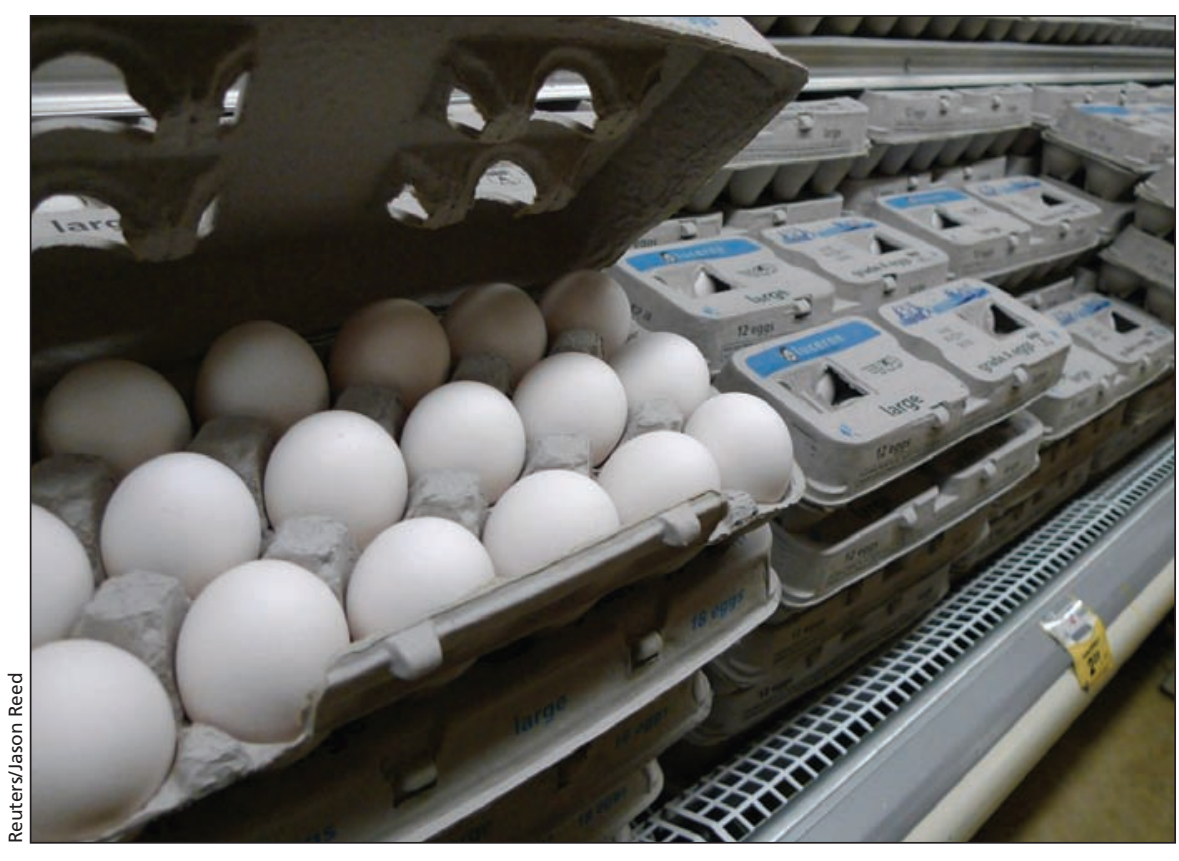

Eggs pictured for sale at a Washington, DC, supermarket during August, when the United States Food and Drug Administration issued several recalls of eggs in a salmonella outbreak.

food safety. "The egg outbreak certainly helps light the fire under the legislation, but you still see how a single member can really stop legislation, even one with such broad-based support."

Senator Tom Coburn, a Republican from Oklahoma and a practising physician, raised a number of objections when he blocked the bill in September, stating on the Senate floor that it would "create a lot of new regulations with a lot of money without solving the real problem." He also argued it wouldn't address the country's disjointed regulatory system, in which more than 15 US agencies have some role in food safety.

Senate Democratic leaders have scheduled a vote to proceed despite Coburn's objections when legislators returned to Congress.

Sandra Eskin, director of the food safety campaign at the Pew Health Group, says it's well past time to update food safety rules whose enforcement fundamentals haven't changed significantly since enactment of the Food and
Drug Act in 1938. While enactment of the legislation wouldn't necessarily have prevented recent significant food outbreaks, she says, the bill contains provisions that probably would have made their impact less severe.

About 76 million food-borne illnesses occur each year in the US, causing more than 300000 hospitalizations and 5000 deaths. The economic impact of such illnesses was estimated at US $\$ 152$ billion a year in a recent study by a former FDA economist, which helps explain the broad-based support for the legislation. Backers include the Grocery Manufacturers Association, which represents food and beverage companies.

Martin Bucknavage, a food safety expert with Penn State University's Department of Food Science, says the food industry has a lot to gain if the legislation can help build public confidence in the food supply.

DeWaal says one of the most significant aspects of the legislation is its emphasis on prevention. While FDA 
inspectors currently do spot checks when visiting companies, she says, the legislation would require companies to have food safety plans in place that the FDA will evaluate.

One remaining question mark about the legislation is whether it will include a provision to ban bisphenol A from baby bottles, sippy cups, baby food and infant formula. Senator Dianne Feinstein, a Democrat from
California, has announced plans to offer the ban in an amendment on the Senate floor. The synthetic chemical has been linked to reproductive and neurological disorders in animal studies.

Bisphenol A has been banned from all baby bottles in Canada and in eight US states. A number of US manufacturers and retailers already have pledged to stop using it in their products. The US government is conducting studies on its possible harmful effects, but Feinstein has argued that the government should move now to limit exposure.

"It is critical we act now to protect the most vulnerable, our infants and toddlers, from this harmful chemical," she said in announcing plans for the amendment. - Nancy Benac, Washington, DC

DOI:10.1503/cmaj.109-3706 